\title{
TIPHAINE SAMOYAULT, Traduction et violence
}

\section{Luana Doni}

\section{(2) OpenEdition \\ Journals}

\section{Edizione digitale}

URL: https://journals.openedition.org/studifrancesi/45705

DOI: $10.4000 /$ studifrancesi.45705

ISSN: 2427-5856

\section{Editore}

Rosenberg \& Sellier

\section{Edizione cartacea}

Data di pubblicazione: 1 août 2021

Paginazione: 427-428

ISSN: 0039-2944

\section{Notizia bibliografica digitale}

Luana Doni, «TiPHAINE SAmoyault, Traduction et violence», Studi Francesi [Online], 194 (LXV | II) | 2021, online dal 01 septembre 2021, consultato il 15 octobre 2022. URL: http://journals.openedition.org/ studifrancesi/45705 ; DOI: https://doi.org/10.4000/studifrancesi.45705

Questo documento è stato generato automaticamente il 15 octobre 2022.

\section{(c)}

Creative Commons - Attribuzione - Non commerciale - Non opere derivate 4.0 Internazionale - CC BYNC-ND 4.0

https://creativecommons.org/licenses/by-nc-nd/4.0/ 


\title{
TIPHAINE SAMOYAULT, Traduction et violence
}

\author{
Luana Doni
}

\section{NOTIZIA}

TIPHAINE SAMOYAUlt, Traduction et violence, Paris, Seuil, Fiction \& Cie, 2020, 208 pp.

1 Distopica e volutamente allarmante, la riflessione di TIPHAINE SAMOYAULT si apre con una funesta constatazione dell'ormai prossima morte della traduzione manuale, assassinata da tutte quelle forme di traduzione digitale, sempre più sofisticate, che rischiano di annientare qualsivoglia fruttuoso incontro tra idiomi diversi.

2 La mutazione, dovuta all'efficacia degli algoritmi dietro allo strumento di traduzione digitale, è di tipo economico e cognitivo e fa del traduttore stesso uno strumento al servizio della macchina.

3 Il lavoro del traduttore diventa così un lavoro di verifica e correzione e non di proposta e ricerca, costringendolo a subordinarsi ad una sorta di globish che sacrifica lentamente gli idiomi meno diffusi.

4 Secondo Samoyault, la violenza è prima di tutto legata all'uso della lingua; esclusiva più che inclusiva, la lingua è responsabile del sentimento di distanza basato sulla cattiva interpretazione del senso. Il volume ha come oggetto l'indagine intorno al conflitto che giace dietro ogni incontro.

5 Da un punto di vista politico, il discorso sulla diversità è corroborato dalle parole di Mikaël Meunier (Direzione generale della traduzione alla Commissione europea), il quale afferma che la mancanza di quel mosaico rappresentato dalla diversità religiosa, linguistica ed etnica, causerebbe la morte dell'Europa, come idea e progetto.

6 La diversità è dunque esaltata in quanto strumento armonico, contro la noia dell'omologazione. Samoyault fa notare che la stessa Commissione è responsabile della messa a punto del servizio eTranslation, strumento di traduzione automatica rapida, in 
grado di tradurre in tutte le lingue ufficiali dell'Unione europea. Lo strumento, sebbene non tenga conto della complessità di ogni lingua e banalizzi sensibilmente alcune conversioni, possiede una sostanziale potenzialità di miglioramento che potrebbe rendere la comunicazione umana un supporto obsoleto.

7 E, sebbene l'espressione di Umberto Eco, "la lingua dell'Europa, è la traduzione", possa risultare quasi provocatoria in tal senso, la realtà è che la traduzione non è una lingua ma un'operazione tra lingue. Fare della traduzione una lingua comporterebbe la perdita della conoscenza della lingua di partenza; nel caso dell'esempio di Françoise Nyssen in merito alla traduzione francese come lingua veicolare tra Francia e Libano, ciò che andrebbe a perdersi è proprio la necessità della formazione in lingua araba.

uzione rischia così di diventare un processo egemonico, assimilatore ma, nel discorso democratico forte dell'analisi geopolitica del tradurre, diventa una delle condizioni del superamento del discorso identitario che rende possibile il confronto tra le differenti realtà culturali.

Secondo le riflessioni di Barbara Cassin, non esiste una traduzione, come non esiste una lingua, perché la complessità linguistica permette vari livelli di traducibilità; basti pensare al problema degli 'intraducibili', che per Cassin rappresentano il sintomo della differenza tra le lingue e vengono considerati elemento di grande importanza, foss'anche per la messa in discussione della propria percezione del mondo, la consapevolezza che ogni lingua è una lingua tra le altre e non l'unica.

10 Samoyault affronta successivamente il discorso da un punto di vista storico: l'antagonismo esterno. La questione coloniale, l'etnocentrismo e il ruolo che la traduzione ha avuto per quanto riguarda la questione della dominazione sono evocati dall'autrice mettendo in gioco la presenza di figure storiche controverse quali La Malinche e Felipillo, primi interpreti riconosciuti, visti dapprima come traditori del loro popolo - e, di conseguenza, della loro lingua - e riabilitati invece in epoca contemporanea.

11 La questione dell'antagonismo esterno e dunque della diatriba tra colonizzatori e colonizzati si alterna, in ambito traduttivo, a quello che è l'antagonismo interno. Una prima forma è rappresentata dal rifiuto puro e semplice della traduzione: la distinzione tra buona e cattiva traduzione, secondo la prospettiva adottata da Meschonnic, e quella dell'intraducibile. Quest'ultimo caso risulta essere il più complesso, in quanto può riguardare la lingua o l'interpretazione. Si è di fronte a un fenomeno di intraducibilità quando non è possibile rendere tutte le virtualità semantiche, fonetiche e grafiche comunicate da una parola o da un'espressione. Samoyault propone l'esempio della presunta intraducibilità della poesia.

12 La traduzione porta con sé una doppia violenza: quella dell'atto di tradurre (per il testo, per il traduttore, per la lingua) e il fatto che la traduzione accompagni situazioni di violenza storica. Un conflitto è quasi sempre accompagnato da un problema di traduzione; un piccolo errore dovuto all'inesatta traduzione della macchina può diventare questione di vita o di morte, e numerosi sono gli esempi.

Un'altra questione cruciale è quella secondo la quale la traduzione "distrugge" l'originale. La traduzione è sempre concepita come violenza, come atto blasfemo nei confronti del testo di partenza; Meschonnic parla di "de-scrittura" per evocare il processo di distruzione dell'originale. 
Vi sono i sostenitori della traduzione così detta letterale come Hölderlin, Chateaubriand e Antoine Berman; i traduttori letterali difendono l'idea del testo-copia che, secondo la definizione di Chateaubriand traduttore di Milton, permette al lettore di vedere l'originale in trasparenza, come attraverso un vetro. Tale posizione è fortemente criticata da chi sostiene invece che la traduzione debba dare la sensazione che il testo sia stato scritto in quella lingua in cui, in realtà, è stato tradotto; un esempio è rappresentato dalla traduzione dantesca di André Pézard. Il lavoro di Pézard fa rivivere la bellezza del testo dantesco non calcandone letteralmente la lingua, ma mettendola in comunicazione con quella francese.

Il quinto capitolo propone una riflessione sull'intervento della traduzione in merito all'esperienza concentrazionaria. Nel capitolo 11 di Se questo è un uomo, Primo Levi tenta di tradurre a memoria, dall'italiano al francese, il "Canto di Ulisse" de La Divina Commedia per il compagno Jean. L'autore si scontra con una serie di versi che non arriva a ricordare o a tradurre. Il passaggio è evocato da Samoyault e mette in risalto le affinità tra la traduzione e l'appello alla memoria. Ricordare è tradurre, allegoricamente, cercare tra i ricordi il libro che manca nella lingua che manca, la definizione di testimonianza. Dalla traduzione dipende la sopravvivenza e viceversa, come accade nel frammento di Hurbinek ne La tregua, che muore "libero ma non redento", poiché non sa dire che una sola parola e quella sola parola non appartiene a nessuna lingua.

Il rapporto fra Primo Levi e la traduzione occupa gran parte dell'analisi di Samoyault $L a$ traduction dans les camps, che si conclude con una riflessione in merito al legame tra il concetto di intraducibile e quello di indicibile.

Tradurre e scrivere sono, come afferma Samoyault, due attività prossime ma inverse; la traduzione è negativa, poiché disfa ciò che lo scrittore ha costruito, lo smantella, lo riduce in pezzi e lo ricostruisce. Ma alla traduzione spetta anche il potere comunicativo, l'impegno nella costruzione di un mondo comune, tra le lingue. Tradurre cambia il modo di leggere; non lo si fa più soltanto con gli occhi, ma con la mano, la voce, il corpo nella sua totalità. 